\title{
Conditioned medium mimicking the tumor microenvironment augments chemotherapeutic resistance via ataxia-telangiectasia mutated and nuclear factor- $\kappa B$ pathways in gastric cancer cells
}

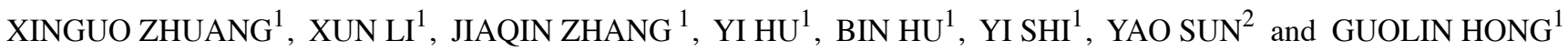 \\ ${ }^{1}$ Department of Laboratory Medicine, The First Affiliated Hospital of Xiamen University, Xiamen, Fujian 361003; \\ ${ }^{2}$ Department of Experimental Medicine, School of Public Health, Xiamen University, Xiamen, Fujian 361005, P.R. China
}

Received January 9, 2018; Accepted July 24, 2018

DOI: $10.3892 /$ or.2018.6637

\begin{abstract}
The tumor microenvironment affects the processes involved in the development of gastric cancer and contributes to multidrug resistance (MDR). Although the metabolism of gastric cancer cells is known to be associated with the development of the tumor microenvironment, the exact role of metabolism in microenvironment-induced MDR formation remains unclear. In the present study, conditioned medium (CM) formed through the metabolism of SGC-7901 gastric carcinoma cells was used to mimic the tumor microenvironment. The effects of CM on drug resistance were evaluated in gastric carcinoma cells. The results revealed that $\mathrm{CM}$ was not only able to upregulate the expression levels of ATP-binding cassette subfamily G member 2 (ABCG2) and MDR-associated protein 2 (MRP2), but also upregulated the expression of certain anti-apoptotic proteins in SGC-7901 cells. In addition, $\mathrm{CM}$ activated the ataxia-telangiectasia mutated (ATM) and NF- $\kappa$ B pathways, while CM-induced ABCG2, MRP2 and anti-apoptotic protein upregulation was impaired by ATM and $N F-\kappa B$ inhibitors. The results of the present study indicated that $\mathrm{CM}$ augmented chemotherapeutic resistance by activating the ATM and $\mathrm{NF}-\kappa \mathrm{B}$ pathways in gastric cancer cells, and that these pathways may be potential therapeutic targets for cases of chemotherapeutic resistance in gastric cancer.
\end{abstract}

\section{Introduction}

Gastric cancer, which is a leading cause of cancer-associated mortality (1), does not respond well to surgery or radiation therapy due to tumor metastases and high recurrence rates $(2,3)$. In the initial stages of the disease, a relatively good response

Correspondence to: Professor Guolin Hong, Department of Laboratory Medicine, The First Affiliated Hospital of Xiamen University, 55 Zhenhai Road, Xiamen, Fujian 361003, P.R. China E-mail: 18860089899@139.com

Key words: conditioned medium, microenvironment, chemotherapeutic resistance, ataxia-telangiectasia mutated, nuclear factor- $\kappa \mathrm{B}$, gastric cancer can be achieved with chemotherapy; however, the formation of multidrug resistance (MDR) alongside treatment presents a challenge $(4,5)$. MDR has been primarily ascribed to functional gene mutations, or to epigenetic changes at the cellular level that influence the uptake, metabolism and/or export of anticancer drugs from individual tumor cells (6). However, substantial evidence has suggested that tumor cells that are sensitive to anticancer drugs in a tissue culture may be resistant when grown in contact with each other as a tumor $(7,8)$. Hence, numerous studies have focused heavily on how the tumor microenvironment influences the resistance of solid tumors to chemotherapy (5).

Tumor tissues comprise cancer cells, fibroblasts and immune cells $(9,10)$, which not only secrete a number of soluble factors, including growth factors, cytokines and chemokines $(11,12)$, but also contribute to the presence of hypoxia and acidity (13). It is reported that each of these components varies in different tumor types $(14,15)$, and has the potential to influence drug resistance (10,16-18). Gastric cancer, as a solid tumor, is mainly composed of gastric cancer cells (3). The metabolism of gastric cancer cells is a dominant factor affecting the properties of the tumor microenvironment (6). However, to date, few studies have been performed to evaluate the effect of tumor cell metabolism on the microenvironment with regard to MDR formation. To investigate the effect of the tumor microenvironment, as formed by gastric cancer cell metabolism, on drug resistance, the present study developed a predictive simulation model in the form of a conditioned medium (CM) in vitro $(15,19)$. The factors secreted by tumor cells in CM include metabolites, cytokines and growth factors, which have good interactions with gastric cancer cells (6), and are similar to the levels present in the in vivo microenvironments. Thus, CM simulates tumor cell metabolism to form the tumor microenvironment, and provides a convenient experimental system to study the association between the tumor microenvironment formed by tumor cell metabolism and inherent resistance (15).

$\mathrm{CM}$ contains a large number of factors, and is likely to simultaneously stimulate various cellular pathways involved in the drug resistance of patients with cancer $(10,19-22)$. Ataxiatelangiectasia mutated (ATM), as a nuclear serine-threonine kinase, is involved in cell cycle checkpoints and DNA double-strand break (DSB) repair (23). It has been reported that ATM was able to upregulate MDR-associated gene and 
protein expression, and contributed to chemoresistance (24). For instance, Yang et al (25) reported that DNA damage induced by chemotherapy resulted in the formation of a large cytosolic complex, namely ATM/NEMO/RIP1, which mediated the NF- $\kappa \mathrm{B}(\mathrm{p} 65 / \mathrm{p} 50)$ heterodimer by activating the IKK complex (26). It has also been reported that $\mathrm{NF}-\kappa \mathrm{B}$ activation mediated the expression of drug efflux pumps, including MDR-associated protein 2 (MRP2) and ATP-binding cassette subfamily $G$ member 2 (ABCG2), and initiated anti-apoptotic protein expression, contributing to chemoresistance (27). Furthermore, it has been identified that ATM can be activated by treatment with interleukin (IL)- 6 without apparent DNA damage. For example, in lung cancer, IL-6 can increase the phosphorylation of ATM and NF- $\mathrm{AB}$ in order to elevate the expression levels of ABCG2, B-cell lymphoma 2 (Bcl-2), myeloid cell leukemia 1 (Mcl-1) and Bcl-extra large (Bcl-xL) (16). However, information in the literature regarding the involvement of $\mathrm{ATM} / \mathrm{NF}-\kappa \mathrm{B}$ signaling in $\mathrm{CM}$-induced MDR formation is currently limited. Therefore, the question is raised of whether ATM can be activated by treatment with CM, which, in turn, augments MDR-associated protein expression and contributes to MDR in gastric cancer.

In the present study, CM was utilized to simulate tumor cell metabolism in order to construct the tumor microenvironment, and observed the effects on inherent resistance in gastric cancer cells. It was revealed that $\mathrm{CM}$ was able to upregulate ABCG2, MRP2 and anti-apoptotic protein expression levels by activating the ATM and NF- $\kappa$ B pathways, thus augmenting SGC-7901 cell chemotherapeutic resistance.

\section{Materials and methods}

Reagents. Camptothecin and cisplatin were purchased from EMD Millipore (Calbiochem; Billerica, MA, USA). Anti-phospho- IKK $\alpha / \beta(1: 1,000$; cat. no. 2697), anti- IKK $\beta$ (1:1,000; cat. no. 2678), anti-p65 (1:1,000; cat. no. 6956), anti-phospho-p65 (1:1,000; cat. no. 13346), anti-ATM (1:1,000; cat. no. 92356), anti-phospho-ATM (1:1,000; cat. no. 4526), anti-ABCG2 (1:1,000; cat. no. 4477S), anti-MRP2 (1:1,000; cat. no. 4446), anti-Bcl-2 (1:1,000; cat. no. 15071S), anti-Bcl-xL (1:1,000; cat. no. 2764), anti-Mcl-1 (1:1,000; cat. no. 94296S), HRP-conjugated anti-rabbit IgG $(1: 3,000$; cat. no. 7074$)$ and HRP-conjugated anti-mouse IgG (1:3,000; cat. no. 7076) were acquired from Cell Signaling Technology, Inc. (Beverly, MA, USA). The ATM phosphorylation inhibitor CGK was purchased from Sigma-Aldrich (Merck KGaA, Darmstadt, Germany). The p65 phosphorylation inhibitor BAY was purchased from Cayman Chemical (Ann Arbor, MI, USA). An Annexin V/propidium iodide (PI) detection kit was obtained from Nanjing KeyGen Biotech Co., Ltd., (Nanjing, China). DAPI was purchased from Vector Laboratories, Inc. (Burlingame, CA, USA). Dulbecco's modified Eagle's medium (DMEM) and fetal bovine serum (FBS) were acquired from GE Healthcare Life Science (Hyclone Laboratories; Logan, UT, USA). Cell Counting Kit-8 (CCK-8) was obtained from Dojindo Molecular Technologies, Inc. (Kumamoto, Japan).

\section{Cell culture and collection of conditioned media}

Cell line and culture conditions. Human gastric cancer (SGC-7901) cells were kindly provided by the Assistant
Professor Zeng Fu Xue (The First Affiliated Hospital of Xiamen University, Xiamen, China). Cells were maintained in our laboratory and grown in DMEM supplemented with $10 \% \mathrm{FBS}$ at $37^{\circ} \mathrm{C}$ and $5 \% \mathrm{CO}_{2}$.

Obtaining CM. According to a previously described method (15), the SGC-7901 cells $\left(1 \times 10^{6}\right)$ were seeded in a 90-mm culture dish (Corning Inc., Corning, NY, USA) in $10 \mathrm{ml}$ complete medium for $48 \mathrm{~h}$. The medium was collected from these cultures under sterile conditions, followed by centrifugation at $1,500 \times \mathrm{g}$ for $10 \mathrm{~min}$ at $25^{\circ} \mathrm{C}$, and then the supernatant was collected as the $\mathrm{CM}$ and stored at $-20^{\circ} \mathrm{C}$ until required for further use. In the present study, $\mathrm{CM}$ is defined as a conditioned medium collected from SGC-7901 cells and used for experiments in the same cells. Plain medium (PM), which consisted of complete medium without cell incubation, served as the control under the same experimental conditions (19).

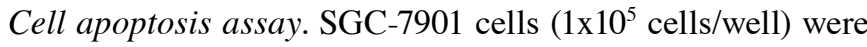
seeded in 6-well plates in $2 \mathrm{ml}$ of PM or increasing \% of CM $(25,50,75$ and $100 \%)$ at $37^{\circ} \mathrm{C}$ for $6 \mathrm{~h}$. Next, the cells were treated with cisplatin $(2 \mu \mathrm{g} / \mathrm{ml})$ for $12 \mathrm{~h}$, and the medium was then replaced with new respective CM and PM without the drug. After $24 \mathrm{~h}$, cells were trypsinized, rinsed with PBS, and incubated with $2 \mu \mathrm{l}$ Annexin V-FITC and $2 \mu \mathrm{l}$ PI for 20 min prior to FACS analysis. The data were analyzed with CellQuest Pro software (BD Biosciences, San Jose, CA, USA).

Cell viability assay. Cell proliferation was determined using a CCK-8 assay. Briefly, SGC-7901 cells (5,000 cells/well) were seeded into 96 -well plates containing $100 \mu \mathrm{l}$ of PM or increasing $\%$ of $\mathrm{CM}(25,50,75$ and $100 \%)$ at $37^{\circ} \mathrm{C}$ for $6 \mathrm{~h}$. Next, the cells were treated with cisplatin $(2 \mu \mathrm{g} / \mathrm{ml})$ or camptothecin (50 $\mu \mathrm{g} / \mathrm{ml}$ ) for $12 \mathrm{~h}$, following which the medium was replaced with new respective CM and PM without drugs. After $36 \mathrm{~h}$ of incubation, $10 \mu \mathrm{l}$ of CCK-8 reagent was added to each well and incubated at $37^{\circ} \mathrm{C}$ for $2 \mathrm{~h}$. Finally, the optical density (OD) of each well was measured at $450 \mathrm{~nm}$ using a spectrophotometer.

Cell clonogenicity assay. SGC-7901 cells (5,000 cells/well) were seeded in 6-well plates in $2 \mathrm{ml}$ of PM or increasing \% of $\mathrm{CM}(25,50,75$ and $100 \%)$ at $37^{\circ} \mathrm{C}$ for $6 \mathrm{~h}$. Next, the cells were treated with cisplatin $(2 \mu \mathrm{g} / \mathrm{ml})$ or camptothecin $(50 \mu \mathrm{g} / \mathrm{ml})$ in $\mathrm{PM}$ and respective $\mathrm{CM}$ for $12 \mathrm{~h}$. The medium was replaced with new PM and respective CM without drugs every 2 days. After 10 days, when colony formation was observed, the cells were fixed in formaldehyde and stained with crystal violet solution (10). Excess crystal violet solution was removed by rinsing the plate under running tap water. Subsequent to drying, each well was destained with $1 \mathrm{ml} \mathrm{33 \%}$ acetic acid, and the optical density (OD) of the resulting colored solution was measured at $595 \mathrm{~nm}$ using a spectrophotometer (19).

Confocal fluorescence microscopy analysis. The effect of ATM and p65 phosphorylation were investigated by confocal fluorescence microscopy. Briefly, SGC-7901 cells (5,000 cells/well) were cultured in FBS-free medium on glass coverslips and incubated for $12 \mathrm{~h}$. The SGC-7901 cells were treated with CM or PM for a desired period of incubation $(0,1$ and $3 \mathrm{~h})$. The cells were then fixed and permeabilized 


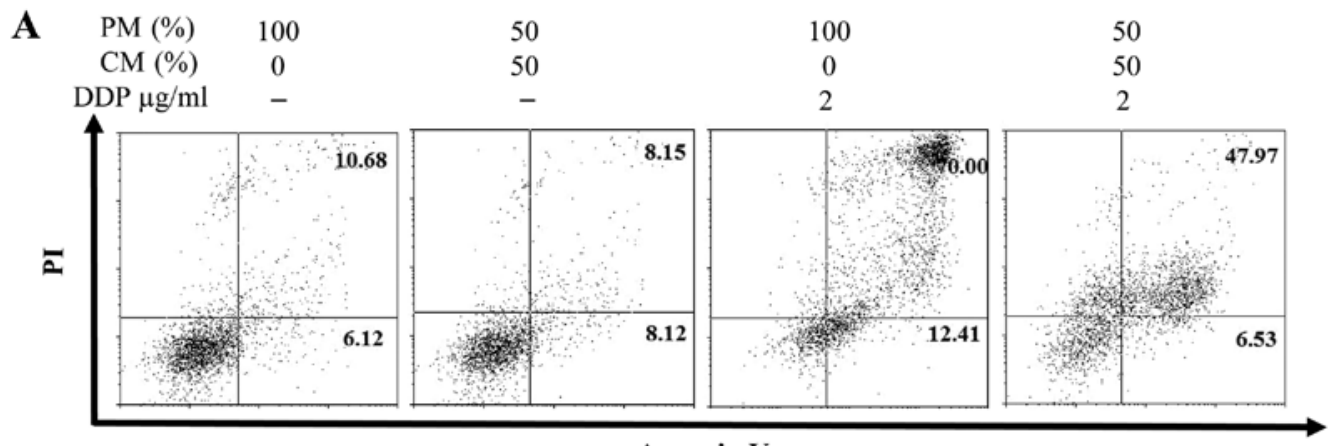

Annexin V

B

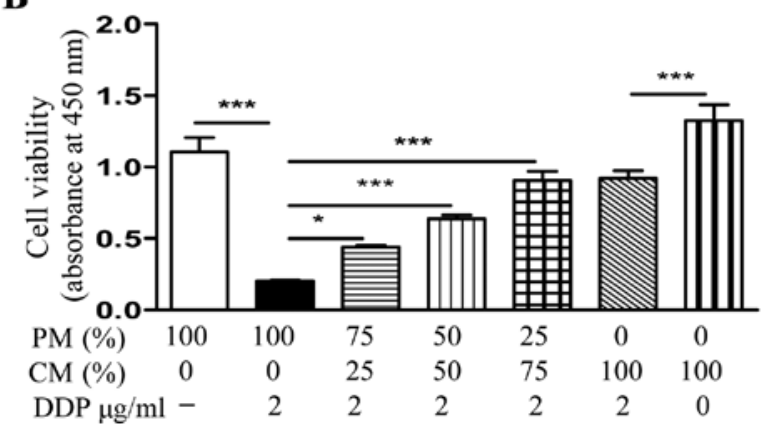

C

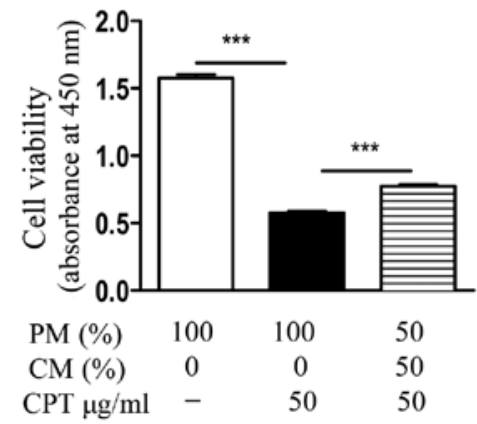

D
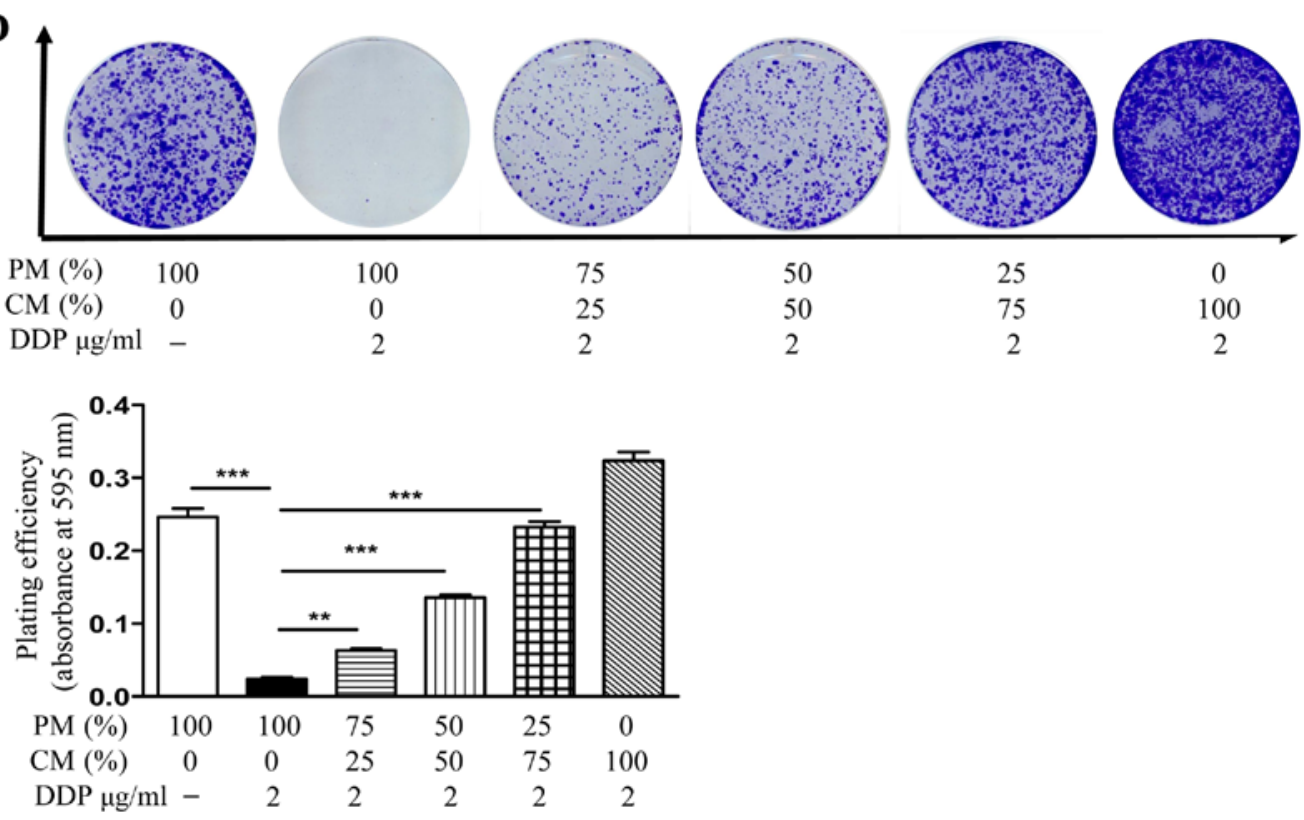

E
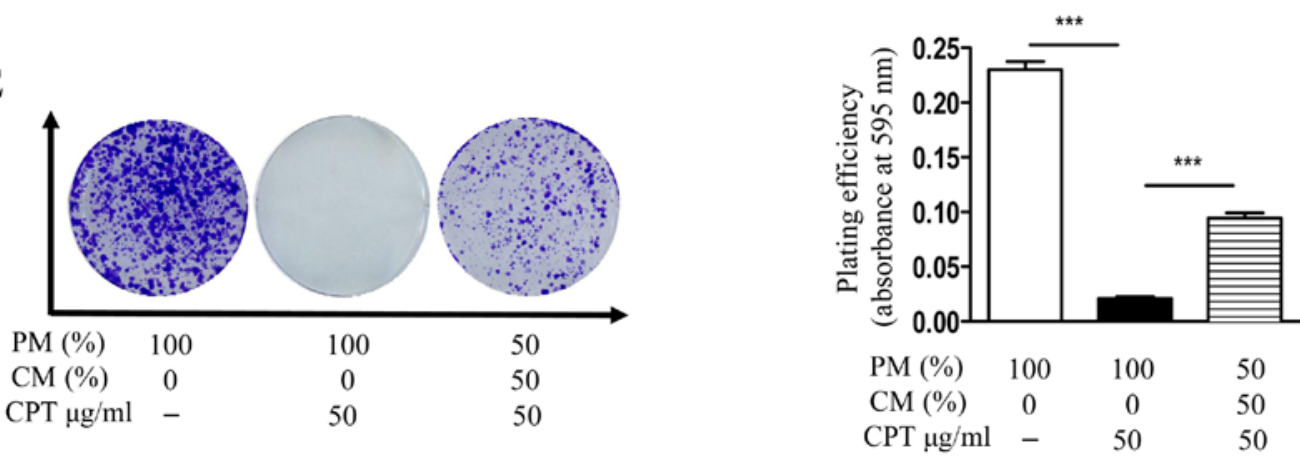

Figure 1. Treatment with CM contributes to chemotherapeutic resistance in SGC-7901 gastric cancer cells. SGC-7901 cells were incubated with the indicated concentrations of CM or control PM, followed by treatment with $2 \mu \mathrm{g} / \mathrm{ml}$ DDP or $50 \mu \mathrm{g} / \mathrm{ml} \mathrm{CPT}$ for $12 \mathrm{~h}$, and replacement of the medium with PM and CM without drugs. (A) Cell apoptosis was determined using Annexin-V/PI staining and flow cytometry after $24 \mathrm{~h}$ of incubation. (B) DDP-treated and (C) CPT-treated cells were subjected to cell viability measurement with a Cell Counting Kit-8 assay after $36 \mathrm{~h}$ of incubation. (D) DDP-treated and (E) CPT-treated cells were subjected to cell clonogenicity examination by crystal violet staining and quantification after 10 days of incubation. Data are presented as the mean \pm standard error of the mean, and are representative of three independent experiments $(\mathrm{n}=3)$. ${ }^{*} \mathrm{P}<0.05,{ }^{* *} \mathrm{P}<0.01$ and ${ }^{* * *} \mathrm{P}<0.001$ (one-way analysis of variance with post hoc Newman-Keuls test). CM, conditioned medium; PM, plain medium; DDP, cisplatin; CPT, camptothecin; PI, propidium iodide. 
A

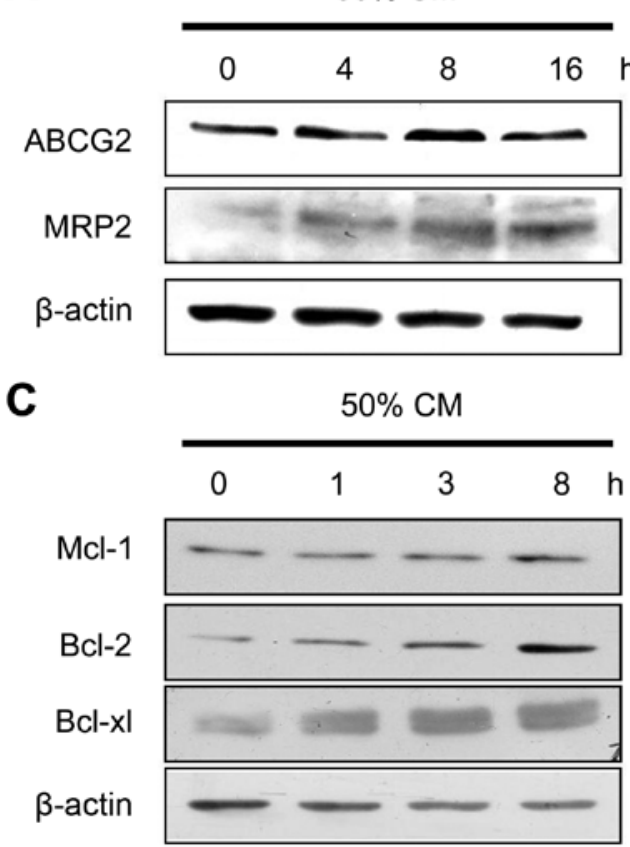

B

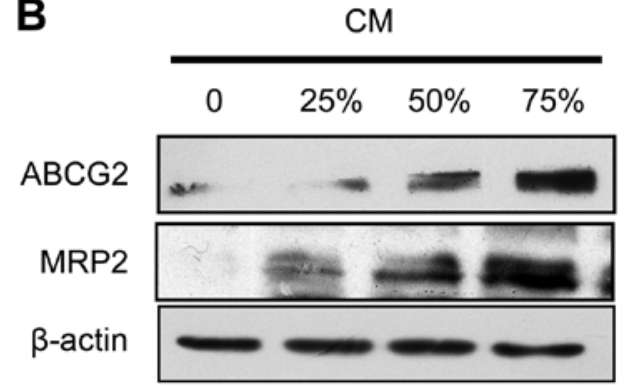

D
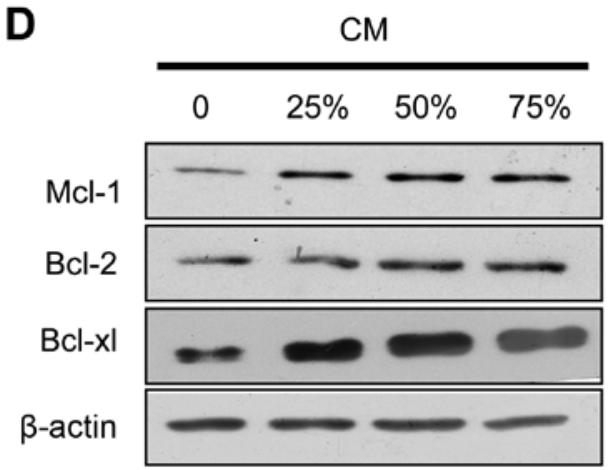

Figure 2. Treatment with CM upregulates the expression levels of MDR and anti-apoptotic proteins in SGC-7901 cells. SGC-7901 cells were grown in plain medium overnight, and then treated with CM. The MDR proteins ABCG2 and MRP2 were examined by western blotting in cells treated with (A) CM (50\%) for the indicated periods, or (B) the indicated percentage of CM for $8 \mathrm{~h}$. Anti-apoptotic Bcl-2, Bcl-xL and Mcl-1 protein levels were determined by western blotting in cells treated with (C) CM (50\%) for the indicated periods, or (D) the indicated percentage of CM for $8 \mathrm{~h}$. $\beta$-actin was used as the loading control. Data shown are representative of three independent experiments $(n=3)$. CM, conditioned medium; ABCG2, ATP-binding cassette subfamily G member 2; MRP2, MDR-associated protein 2; Bcl-2, B-cell lymphoma 2; Bcl-xL, Bcl-extra large; Mcl-1, myeloid cell leukemia 1.

with $100 \%$ methanol at $25^{\circ} \mathrm{C}$ for $15 \mathrm{~min}$. Subsequently, the cells were blocked with $10 \%$ non-fat milk for $3 \mathrm{~h}$ at $25^{\circ} \mathrm{C}$ and then incubated with primary antibodies (phospho-p65 or phospho-ATM) overnight at $4^{\circ} \mathrm{C}$, followed by staining with goat anti-rabbit IgG-PE (1:1,000 dilution; Abcam, San Francisco, CA, USA) for $1 \mathrm{~h}$ at $37^{\circ} \mathrm{C}$. Finally, cells were stained with DAPI to visualize the nuclei. Images were captured using a confocal fluorescence microscope (Olympus Corp., Tokyo, Japan) at $546 \mathrm{~nm}$. The ATM phosphorylation inhibitor CGK $(20 \mu \mathrm{M})$ and the $\mathrm{p} 65$ phosphorylation inhibitor BAY $(20 \mu \mathrm{M})$ were respectively used to pretreat the cells for $1 \mathrm{~h}$ prior to $\mathrm{CM}$ treatment to observe the effects of ATM and p65 phosphorylation on the expression of MDR proteins and anti-apoptotic proteins.

Western blotting. To investigate the effects of $\mathrm{CM}$ on MDR-associated gene expression, the proteins of SGC-7901 cells treated with CM were obtained using RIPA buffer (Beyotime Institute of Biotechnology, Shanghai, China), and then their expression was determined via western blot analysis. The protein concentration was determined by BCA assay (Micro BCA Protein Determination kit; Thermo Fisher Scientific Inc., Waltham, MA, USA). Protein lysates were resolved via $8 \%$ SDS-PAGE and then transferred to polyvinylidene difluoride membranes. The membranes were blocked with $5 \%$ fat-free milk for $2 \mathrm{~h}$ at $25^{\circ} \mathrm{C}$, and then they were incubated with the primary antibodies (ATM, p-ATM, p65, p-p65, p-IKK $\alpha / \beta$, ABCG2, MRP2, Bcl-2, Bcl-Xl and Mcl-1) at $4^{\circ} \mathrm{C}$ for $12 \mathrm{~h}$, followed by the appropriate peroxidase-conjugated secondary antibodies (HRP-conjugated anti-rabbit IgG and HRP-conjugated anti-mouse $\operatorname{IgG}$ ) at $25^{\circ} \mathrm{C}$ for $1.5 \mathrm{~h}$. The bound antibodies were detected by enhanced chemiluminescence (ECL; Beyotime Institue of Biotechnology). $\beta$-actin was used as the loading control.

Statistical analysis. All data are expressed as the mean \pm standard error of the mean. The results were statistically analyzed using GraphPad Prism (version 6.0; GraphPad Software, Inc., La Jolla, CA, USA) by one-way analysis of variance with a post hoc Newman-Keuls test. $\mathrm{P}<0.05$ was considered to indicate a statistically significant difference.

\section{Results}

Treatment with CM contributes to chemotherapeutic resistance in SGC-7901 gastric cancer cells. To explore the role of $\mathrm{CM}$ in the development of innate resistance to therapy in gastric cancer, SGC-7901 cells were treated with camptothecin or cisplatin in $\mathrm{CM}$ and then compared with the PM-treated controls. The effects of CM on gastric cancer cell viability, apoptosis and growth were observed. The results revealed that 50\% CM significantly reversed SGC-7901 cell apoptosis induced by cisplatin, as determined by Annexin V staining (Fig. 1A). A CCK-8 assay also confirmed that CM reversed the trend of reduced SGC-7901 cell viability induced by camptothecin or cisplatin in a concentration-dependent manner (Fig. 1B and C). Analysis of the percentage of microcolonies also indicated that $\mathrm{CM}$ efficiently increased the SGC-7901 cell survival and growth rates following cisplatin treatment in a concentration-dependent manner (Fig. 1D and E). Collectively, these data indicated that $\mathrm{CM}$ was able to reverse the apoptosis induced by camptothecin 
A

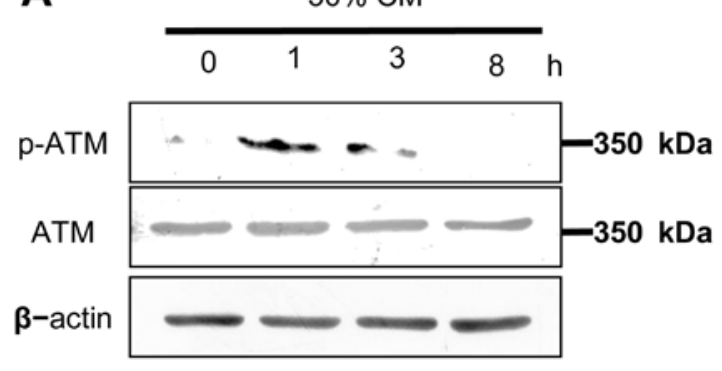

B

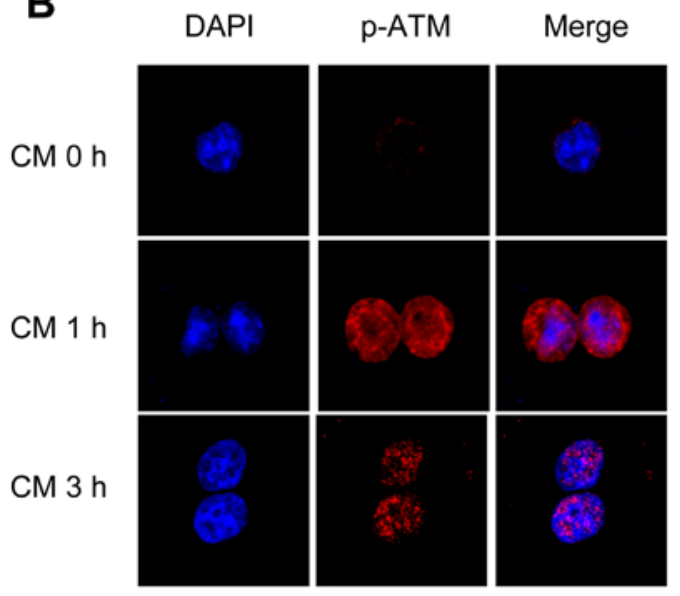

Figure 3. Treatment with CM induces ATM phosphorylation in SGC-7901 cells. SGC-7901 cells were treated with CM (50\%) for the indicated periods. ATM phosphorylation was determined via (A) western blotting and (B) confocal fluorescence microscopy (magnification, x60). Data shown are representative of three independent experiments $(n=3)$. $\beta$-actin was used as the loading control. CM, conditioned medium; ATM, ataxia-telangiectasia mutated; p-ATM, phosphorylated ATM.

and cisplatin, contributing to the chemotherapeutic resistance of gastric cancer.

$C M$ upregulates the expression of MDR proteins and anti-apoptosis proteins in SGC-7901 cells. To investigate the effects of CM on the expression of MDR proteins and anti-apoptotic proteins in SGC-7901 cells, the cells were treated with $\mathrm{CM}$, and the expression levels of $\mathrm{ABCG} 2, \mathrm{MRP} 2$, $\mathrm{Bcl}-2, \mathrm{Bcl}-\mathrm{xL}$ and $\mathrm{Mcl}-1$ were determined via western blotting. The results demonstrated that $\mathrm{CM}$ stimulation increased ABCG2 and MRP2 expressions in a time-(4-16 h) (Fig. 2A) and concentration-dependent manner (25-75\%) (Fig. 2B), which reach the maximum at $8 \mathrm{~h}$ and $75 \% \mathrm{CM}$, respectively. markedly increased ABCG2 expression, and slightly increased MRP2 expression (Fig. 2A and B). CM stimulation (50\%) markedly increased Bcl-2 and Bcl-xL expression levels in a time-dependent manner, and slightly increased $\mathrm{Mcl}-1$ expression (Fig. 2C). CM stimulation also increased Bcl-2, Bcl-xL and Mcl-1 expression in a concentration-dependent manner (Fig. 2D), which reached the maximum at 50\% CM. Collectively, these data indicated that $\mathrm{CM}$ was able to upregulate the expression of MDR proteins and anti-apoptotic proteins, contributing to drug resistance in SGC-7901 cells.

CM activates ATM in SGC-7901 cells. ATM, as a serine/ threonine protein kinase, may be activated by DNA DSBs,
A $50 \% \mathrm{CM}$
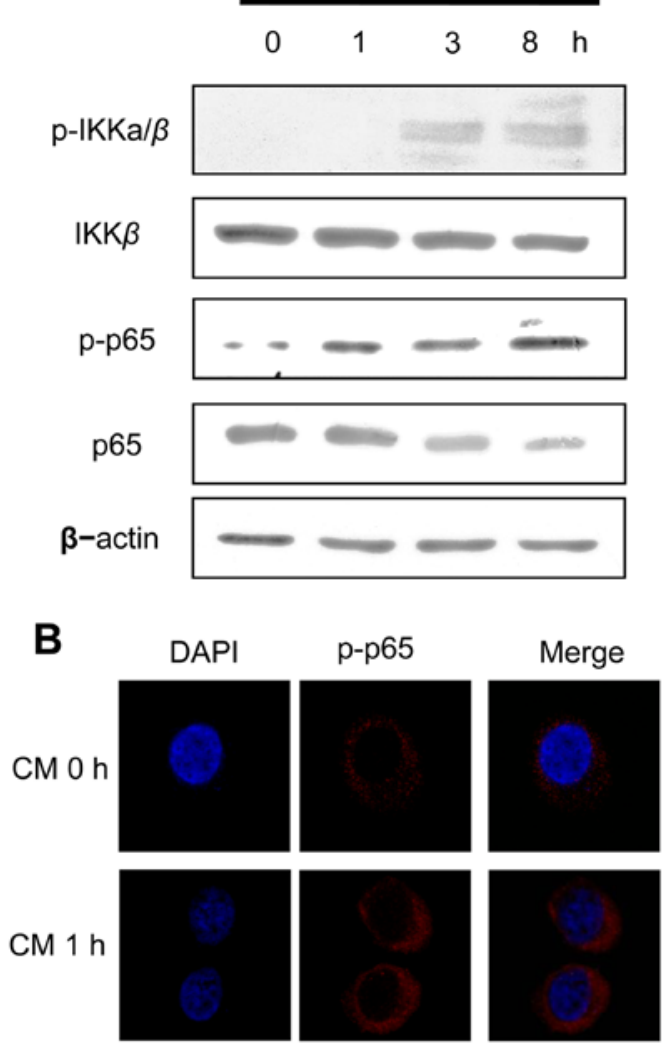

$\mathrm{CM} 3 \mathrm{~h}$
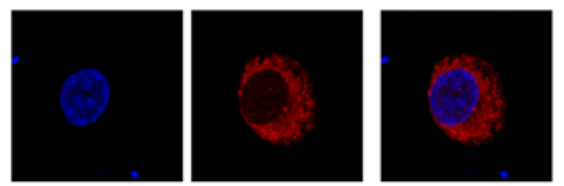

Figure 4. CM induced IKK $\alpha / \beta$ and p65 phosphorylation in SGC-7901 cells treated with CM $(50 \%)$ for the indicated time periods. IKK $\alpha / \beta$ and $\mathrm{p} 65$ phosphorylation was determined via (A) western blotting and (B) confocal fluorescence microscopy (magnification, x60). Data shown are representative of three independent experiments $(n=3)$. $\beta$-actin was used as the loading control. CM, conditioned medium; p-, phosphorylated.

which are induced by certain chemotherapy drugs. In addition, activated ATM regulates distinct downstream pathways to repair damaged DNA and contributes to MDR $(23,27)$. To investigate whether CM activated ATM in gastric cancer cells, SGC-7901 cells were treated with CM, and the level of ATM phosphorylation was determined via western blotting (Fig. 3A) and confocal fluorescence microscopy (Fig. 3B). It was observed that CM markedly increased ATM phosphorylation in SGC-7901 cells in a time-dependent manner, and that ATM phosphorylation reached a maximum at $1 \mathrm{~h}$ following exposure to $\mathrm{CM}$. These results indicated that $\mathrm{CM}$ activated the ATM pathway in gastric cancer cells.

CM activates the NF- $\kappa B$ signaling pathway in SGC-7901 cells. The importance of NF- $\mathrm{KB}$ in the chemotherapy resistance of tumor cells is increasingly acknowledged, and it is well-established that phosphorylated IKK $\alpha / \beta$ is an important prerequisite for NF- $\kappa B$ activation (28). To determine the effect of CM on IKK $\alpha / \beta$ and p65 activation in gastric cancer, SGC-7901 cells were treated with $\mathrm{CM}$, and the phosphorylation of IKK $\alpha / \beta$ and p65 was observed using western blotting (Fig. 4A). The 
A

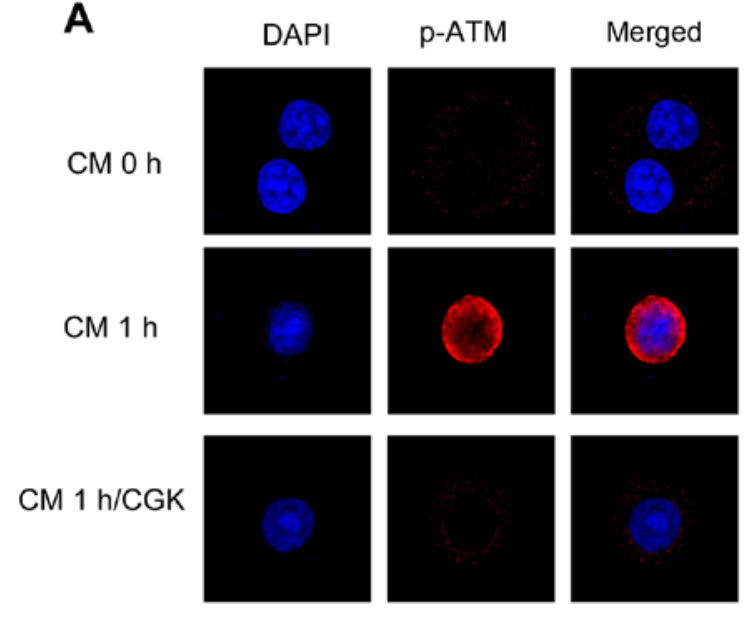

C

$\begin{array}{ccccc}\text { PM (\%) } & 100 & 50 & 50 & 50 \\ \text { CM (\%) } & 0 & 50 & 50 & 50 \\ \text { DMSO } & + & + & - & - \\ \text { CGK } 20 \mu \mathrm{M} & - & - & + & - \\ \text { BAY } 20 \mu \mathrm{M} & - & - & - & +\end{array}$

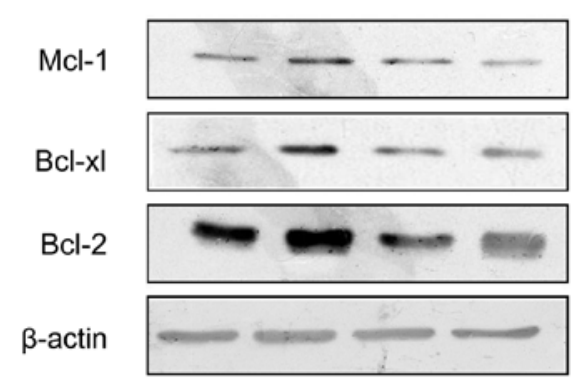

B

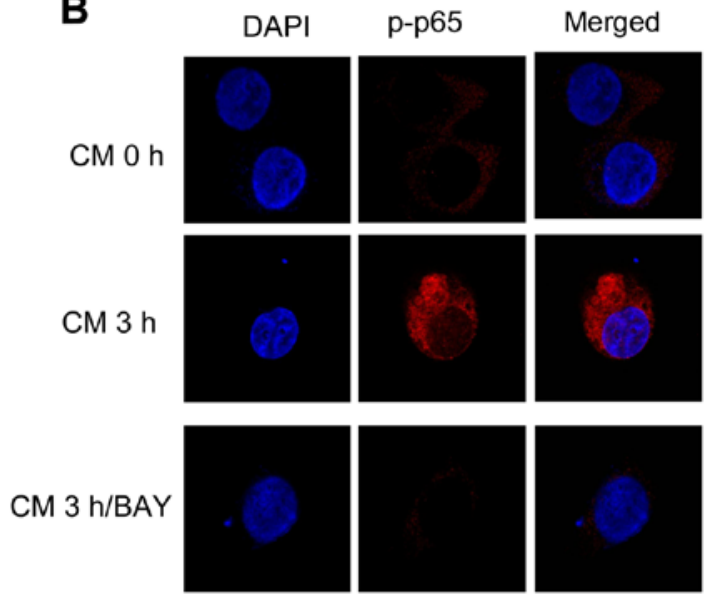

D

\begin{tabular}{|c|c|c|c|}
\hline PM (\%) & 100 & 50 & 50 \\
\hline CM (\%) & 0 & 50 & 50 \\
\hline DMSO & + & + & - \\
\hline CGK $20 \mu \mathrm{M}$ & - & - & + \\
\hline BAY $20 \mu \mathrm{M}$ & - & - & - \\
\hline
\end{tabular}

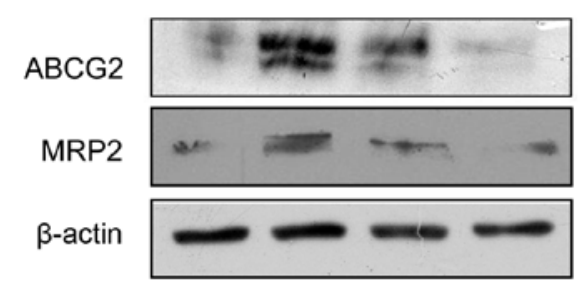

Figure 5. CM upregulates the expression of ABCG2, MRP2 and anti-apoptotic proteins by activating the ATM and nuclear factor- $\kappa \mathrm{B}$ pathways. SGC-7901 cells were pretreated with the inhibitors BAY and CGK at the indicated concentrations $1 \mathrm{~h}$ prior to CM (50\%) 8-h stimulation. (A) ATM and (B) p65 phosphorylation was determined by confocal fluorescence microscopy (magnification, x60). (C) Anti-apoptotic proteins (Mcl-1, Bcl-xL and Bcl-2) and (D) ABCG2 and MRP2 proteins were determined by western blotting. Data shown are representative of three independent experiments (n=3). $\beta$-actin was used as the loading control. CM, conditioned medium; PM, plain medium; ATM, ataxia-telangiectasia mutated; ABCG2, ATP-binding cassette subfamily G member 2; MRP2, MDR-associated protein 2; Mcl-1, myeloid cell leukemia 1; Bcl-xL, Bcl-extra large; Bcl-2, B-cell lymphoma 2.

results revealed that the phosphorylation of IKK $\alpha / \beta$ and $\mathrm{p} 65$ was increased in a time-dependent manner in SGC-7901 cells. These results were validated by observing p65 phosphorylation using confocal fluorescence microscopy (Fig. 4B). Taken together, these findings indicated that $\mathrm{CM}$ also activated the $\mathrm{NF}-\kappa \mathrm{B}$ pathway in gastric cancer cells.

Inhibition of ATM and $N F-\kappa B$ activation abolishes the effects of $C M$ on ABCG2, MRP2 and anti-apoptotic protein expression. To explore whether the ATM and NF- $\mathrm{BB}$ pathways are involved in CM-mediated drug resistance in gastric cancer cells, the ATM phosphorylation inhibitor CGK and NF- $\mathrm{NB}$ inhibitor BAY were used to pretreat SGC-7901 cells for $1 \mathrm{~h}$ prior to CM stimulation. Subsequently, the phosphorylation of ATM and p65 was analyzed by confocal fluorescence microscopy (Fig. 5A and B), while the expression levels of ABCG2, MRP2, Bcl-2, Bcl-xL and Mcl-1 were determined via western blotting (Fig. 5C and D). The results demonstrated that CGK and BAY effectively inhibited ATM and p65 phosphorylation, and that the inhibition of ATM and p65 phosphorylation effectively blocked ABCG2, MRP2, Bcl-2, Bcl-xL and Mcl-1 upregulation induced by $\mathrm{CM}$. These results indicated that the ATM and NF- $\mathrm{B}$ pathways participated in the CM-induced upregulation of ABCG2, MRP2, Bcl-2, Bcl-xL and Mcl-1 in SGC-7901 cells.

Inhibition of ATM and p65 effectively reverses $C M$-induced drug resistance. To further evaluate the roles of ATM and p65 activation in the development of CM-mediated drug resistance in gastric cancer cells, the ATM phosphorylation inhibitor CGK and the NF- $\mathrm{NB}$ inhibitor BAY were used prior to cisplatin stimulation in $\mathrm{CM}$. The results revealed that the usage of CGK and BAY effectively eliminated the increased cancer cell viability induced by $\mathrm{CM}$, as determined by a CCK-8 assay (Fig. 6A). Meanwhile, microscopic observation also demonstrated that the inhibition of ATM and p65 activation reversed the anti-apoptotic effect elicited by CM (Fig. 6B). Taken together, these findings indicated that CM-induced chemotherapeutic resistance in gastric cancer cells occurs, at least in part, via ATM and NF- $\mathrm{BB}$ activation. 


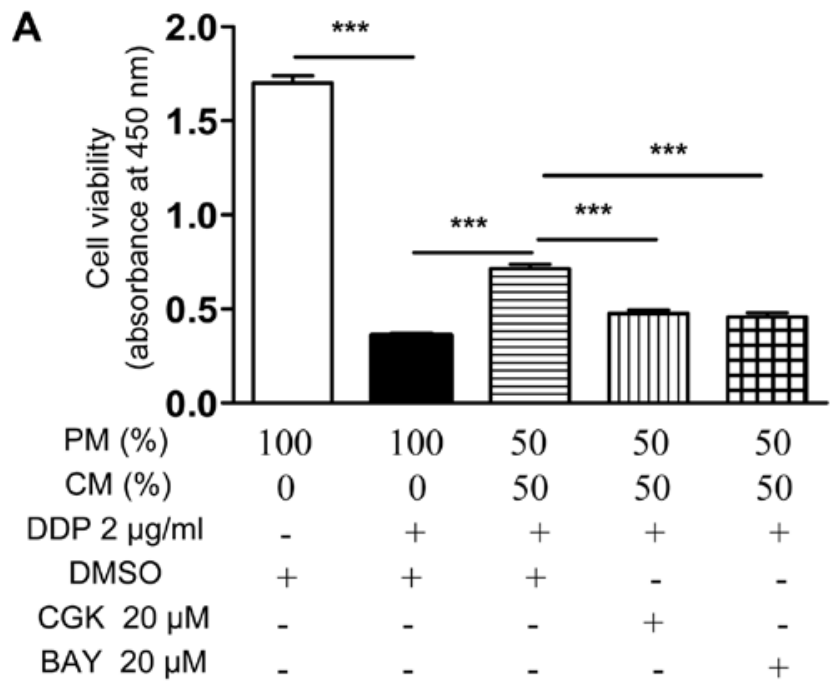

$\begin{array}{cc}\text { B } \mathrm{PM}(\%) & 100 \\ \mathrm{CM}(\%) & 0 \\ \text { DDP } 2 \mu \mathrm{g} / \mathrm{ml} & - \\ \text { DMSO } & + \\ \text { CGK } 20 \mu \mathrm{M} & - \\ \text { BAY } 20 \mu \mathrm{M} & -\end{array}$

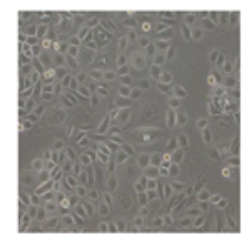

$\begin{array}{cc}100 & 50 \\ 0 & 50 \\ + & + \\ + & + \\ - & - \\ - & -\end{array}$

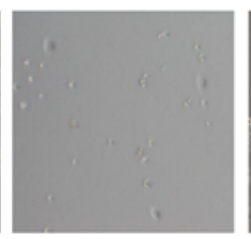

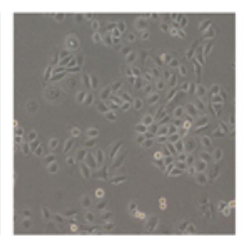

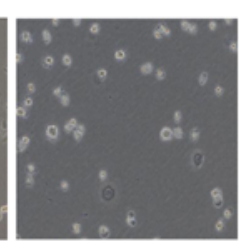

50

50

$+$

-

$-$

$+$

-

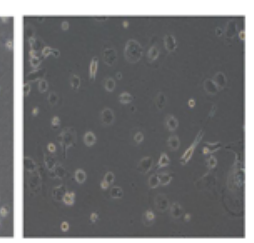

Figure 6. Inhibition of ataxia-telangiectasia mutated and p65 effectively reversed CM-induced drug resistance. SGC-7901 cells were pretreated with the inhibitors BAY and CGK at the indicated concentrations $1 \mathrm{~h}$ prior to CM (50\%) addition. Cells were treated with $2 \mu \mathrm{g} / \mathrm{ml} \mathrm{DDP}$ in CM (50\%) or control PM for $12 \mathrm{~h}$, following which the medium was replaced with PM and CM without DDP. (A) Cell viability was measured by a Cell Counting Kit-8 assay, and (B) the patterns of microcolonies formed and cell morphology were observed under a microscope (magnification, x60). Data are presented as the mean \pm standard error of the mean, and are representative of three independent experiments $(\mathrm{n}=3)$. ${ }^{* * *} \mathrm{P}<0.001$ (one-way analysis of variance with a post hoc Newman-Keuls test). CM, conditioned medium; PM, plain medium; DDP, cisplatin.

\section{Discussion}

Recently, the effect of the tumor microenvironment on drug resistance has received considerable attention $(5,29)$. Although certain studies have evaluated the regulation of tumor drug resistance in response to a few specific factors within the tumor microenvironment, including IL-6, IL-8, hypoxia and low $\mathrm{pH}(10,16,30-32)$, systematic evaluations of the overall effect of the tumor microenvironment on innate resistance to therapy are limited. In the present study, CM was used to simulate the tumor microenvironment in vitro. Compared with single factor analysis, CM is more consistent with the multi-factorial and complex situation in the body, and the levels and ratios of all factors in CM are closer to the true state in the body. Thus, CM provides a convenient microenvironment system for studying drug resistance. The effects of $\mathrm{CM}$ on cell viability, apoptosis and growth, as well as on the expression of MDR-associated proteins, and activation of ATM and $\mathrm{NF}-\kappa \mathrm{B}$, were investigated in the present study. The results indicated that $\mathrm{CM}$ efficiently upregulated the expression of ABCG2, MRP2 and anti-apoptotic proteins via phosphorylation of ATM and NF- $\kappa B$ kinases, and resulted in MDR in gastric cancer. Notably, ATM and $\mathrm{NF}-\kappa \mathrm{B}$ inhibitors abolished the $\mathrm{CM}$-increased drug resistance phenotype, indicating that ATM and $\mathrm{NF}-\kappa \mathrm{B}$ inhibitors may be useful for overcoming MDR in gastric cancer.

A number of reports from different tumor studies indicated that several tumor types are capable of producing and secreting a variety of factors in vitro and in vivo (19,33-35). Desai et al (19) have analyzed the cytokine profile of CM from human cancer cell lines of diverse origin, including lung adenocarcinoma (A549), fibrosarcoma (HT-1080) and glioblastoma (U373MG) cells in vitro. The authors examined the secretion of pro-inflammatory cytokines (TNF- $\alpha$, IL-1 $\beta$ and IL-6), chemokines (fractalkine, IL-8, MCP-1 and IP-10) and growth/pro-angiogenic factors (PDGF-AA, TGF- $\beta$ and VEGF) from A549, HT-1080 and U373MG cells during normal culture conditions. They also demonstrated the qualitative and quantitative changes in the cytokine profile of CM from the three types of human tumor cell lines compared with the PM control. IL-6, IL-8 and VEGF levels were markedly different among the three cell lines, with the highest values observed in HT-1080 cells, and were also significantly different compared 
with the PM control levels. These values were significantly different compared with those in the PM control $(\mathrm{P}<0.05)(15)$. The fact that tumor tissues are composed of tumor cells, fibroblasts and immune cells cannot exclude the possibility that other components of the tumor tissue may also contribute to the elevation of cytokines in vivo, thus, this requires further exploration. However, CM has provided a convenient microenvironment system to consider all cytokines as a whole for studying drug resistance in vitro.

ATM serves a pivotal role in repairing DNA DSBs by chemotherapeutic agents, contributing to chemoresistance in a variety of tumors arising from the lung, endometrium, kidney and melanoma (26). However, it was recently demonstrated that ATM could be activated by IL- 6 and hypoxia treatment without DNA damage (16). In the present study, the data showed that CM was able to activate ATM kinase without apparent DNA damage, and that inhibition of ATM activation abolished the effect of CM on the anti-apoptotic phenotype. All of these results indicate that CM activated ATM kinase to upregulate chemotherapeutic resistance under the conditions of without apparent DNA damage. However, the exact interactions between ATM and specific factors in CM that promote chemotherapeutic resistance require further exploration.

$\mathrm{NF}-\kappa \mathrm{B}$ is an intracellular transcription factor that is important in regulating apoptosis, inflammatory responses, cell survival and immune responses (36). It is also a key inhibitor of apoptotic proteins and a regulator of pro-survival factors (37). A previous study demonstrated that, in camptothecin or cisplatin treatment conditions, NF- $\kappa \mathrm{B}$ activation upregulated ABCG2 and MRP2 expression in small cell lung cancer (27). In the present study, CM treatment activated the IKK complex without DNA damage and increased the phosphorylation of p65 to initiate downstream target gene transcription. Furthermore, inhibition of ATM and $\mathrm{NF}-\kappa \mathrm{B}$ activity eliminated the effect of $\mathrm{CM}$ on ABCG2 and anti-apoptotic protein expression, indicating that the ATM and $\mathrm{NF}-\kappa \mathrm{B}$ pathways are potential therapeutic targets for gastric cancer chemotherapy. However, it remains unclear whether $\mathrm{CM}$-induced NF- $\mathrm{KB}$ activation depends on ATM phosphorylation, and this requires further investigation.

High expression levels of MDR transporters are often involved in drug resistance. ABCG2 and MRP2 are important efflux transporters on the tumor cell surface $(27,38)$, which are able to regulate the intracellular drug concentration by ATP hydrolysis, thereby determining cell sensitivity to chemotherapeutic agents and conferring drug resistance (39-41). In the current study, evidence was obtained that $\mathrm{CM}$ upregulated ABCG2 and MRP2 expression levels. In addition, ABCG2 was recently recognized as cancer stem cell marker (16). The present study revealed that $\mathrm{CM}$ treatment increased ABCG2 expression, indicating that $\mathrm{CM}$ treatment facilitates gastric cancer cells to acquire cancer stem cell-like phenotypes. However, the exact effects of various CM compositions on gastric cancer stem cell marker expression profiles are complex and require further investigation.

In conclusion, the present study utilized $\mathrm{CM}$ to mimic the tumor microenvironment in order to explore the association between the tumor microenvironment and drug resistance. The results demonstrated that $\mathrm{CM}$ was able to upregulate the expression levels of ABCG2, MRP2 and anti-apoptosis proteins in vitro by activating the ATM and $\mathrm{NF}-\kappa \mathrm{B}$ pathways, inducing drug resistance. With this line of understanding, future work should be aimed at validating these findings in vivo to delineate the roles of ATM and $\mathrm{NF}-\kappa \mathrm{B}$ in determining drug resistance induced by the tumor microenvironment. Nevertheless, the results of the present study indicated that ATM and NF- $\kappa$ B are potential therapeutic targets to circumvent drug resistance induced by the tumor microenvironment in the treatment of gastric carcinoma.

\section{Acknowledgements}

Not applicable.

\section{Funding}

The present study was supported by grants from the National Natural Science Foundation of China (nos. 81772287 and 81371902), the National Natural Science Foundation of Fujian (nos. 2016J01643 and 2018J01379) and the Fujian Provincial Health and Family Planning Commission (nos. 2018-2-62, 2017-ZQN-84 and 2018-ZQN-81).

\section{Availability of data and materials}

The datasets used during the present study are available from the corresponding author upon reasonable request.

\section{Authors' contributions}

GH designed the research and copy-edited the paper. XZ and XL conducted the western blot and cell apoptosis assay. JZ conducted the western blot and cell clonogenicity assay; $\mathrm{BH}$ and $\mathrm{YH}$ conducted the confocal microscope assay; YSh and YSu conducted the cell culture and collection of conditioned media and XZ wrote the manuscript. All authors read and approved the manuscript and agree to be accountable for all aspects of the research in ensuring that the accuracy or integrity of any part of the work are appropriately investigated and resolved.

\section{Ethics approval and consent to participate}

Not applicable.

\section{Patient consent for publication}

Not applicable.

\section{Competing interests}

The authors declare that they have no competing interests.

\section{References}

1. Torre LA, Bray F, Siegel RL, Ferlay J, Lortet-Tieulent J and Jemal A: Global cancer statistics, 2012. CA Cancer J Clin 65: 87-108, 2015.

2. Zhao D, Zhang Y and Song L: MiR-16-1 targeted silences far upstream element binding protein 1 to advance the chemosensitivity to adriamycin in gastric cancer. Pathol Oncol Res 24: 483-488, 2018. 
3. Sugano K: Screening of gastric cancer in Asia. Best Pract Res Clin Gastroenterol 29: 895-905, 2015.

4. Wei Z, Liang L, Junsong L, Rui C, Shuai C, Guanglin Q, Shicai H, Zexing W, Jin W, Xiangming C, et al: The impact of insulin on chemotherapeutic sensitivity to 5-fluorouracil in gastric cancer cell lines SGC7901, MKN45 and MKN28. J Exp Clin Cancer Res 34: 64, 2015

5. Correia AL and Bissell MJ: The tumor microenvironment is a dominant force in multidrug resistance. Drug Resist Updat 15: $39-49,2012$.

6. Tredan O, Galmarini CM, Patel K and Tannock IF: Drug resistance and the solid tumor microenvironment. J Natl Cancer Inst 99: 1441-1454, 2007.

7. Kerbel RS, St Croix B, Florenes VA and Rak J: Induction and reversal of cell adhesion-dependent multicellular drug resistance in solid breast tumors. Hum Cell 9: 257-264, 1996.

8. Teicher BA, Herman TS, Holden SA, Wang YY, Pfeffer MR, Crawford JW and Frei E III: Tumor resistance to alkylating agents conferred by mechanisms operative only in vivo. Science 247 $1457-1461,1990$

9. Junttila MR and de Sauvage FJ: Influence of tumour microenvironment heterogeneity on therapeutic response. Nature 501: 346-354, 2013.

10. $\mathrm{Hu} \mathrm{CF}$, Huang YY, Wang YJ and Gao FG: Upregulation of ABCG2 via the PI3K-Akt pathway contributes to acidic microenvironment-induced cisplatin resistance in A549 and LTEP-a-2 lung cancer cells. Oncol Rep 36: 455-461, 2016.

11. Lowe JM, Menendez D, Bushel PR, Shatz M, Kirk EL, Troester MA, Garantziotis S, Fessler MB and Resnick MA p53 and NF-kB coregulate proinflammatory gene responses in human macrophages. Cancer Res 74: 2182-2192, 2014.

12. O'Reilly S, Ciechomska M, Cant R and van Laar JM: Interleukin-6 (IL-6) trans signaling drives a STAT3-dependent pathway that leads to hyperactive transforming growth factor-beta (TGF-beta) signaling promoting SMAD3 activation and fibrosis via Gremlin protein. J Biol Chem 289: 9952-9960, 2014.

13. Greijer AE, de Jong MC, Scheffer GL, Shvarts A, van Diest PJ and van der Wall E: Hypoxia-induced acidification causes mitoxantrone resistance not mediated by drug transporters in human breast cancer cells. Cell Oncol 27: 43-49, 2005.

14. Lathers DM and Young MR: Increased aberrance of cytokine expression in plasma of patients with more advanced squamous cell carcinoma of the head and neck. Cytokine 25: 220-228, 2004

15. Desai S, Kumar A, Laskar S and Pandey BN: Cytokine profile of conditioned medium from human tumor cell lines after acute and fractionated doses of gamma radiation and its effect on survival of bystander tumor cells. Cytokine 61: 54-62, 2013.

16. Yan HQ, Huang XB, Ke SZ, Jiang YN, Zhang YH, Wang YN, $\mathrm{Li} \mathrm{J}$ and Gao FG: Interleukin 6 augments lung cancer chemotherapeutic resistance via ataxia-telangiectasia mutated/NF-kappaB pathway activation. Cancer Sci 105: 1220-1227, 2014.

17. Penson RT, Kronish K, Duan Z, Feller AJ, Stark P, Cook SE Duska LR, Fuller AF, Goodman AK, Nikrui N, et al: Cytokines IL-1beta, IL-2, IL-6, IL-8, MCP-1, GM-CSF and TNFalpha in patients with epithelial ovarian cancer and their relationship to treatment with paclitaxel. Int J Gynecol Cancer 10: 33-41, 2000.

18. Cheng GM and To KK: Adverse cell culture conditions mimicking the tumor microenvironment upregulate ABCG2 to mediate multidrug resistance and a more malignant phenotype. ISRN Oncol 2012: 746025, 2012

19. Desai S, Laskar S and Pandey BN: Autocrine IL-8 and VEGF mediate epithelial-mesenchymal transition and invasiveness via p38/JNK-ATF-2 signalling in A549 lung cancer cells. Cell Signal 25: 1780-1791, 2013.

20. Spanswick VJ,LoweHL,Newton C,Bingham JP,Bagnobianchi A, Kiakos K, Craddock C, Ledermann JA, Hochhauser D and Hartley JA: Evidence for different mechanisms of 'unhooking' for melphalan and cisplatin-induced DNA interstrand cross-links in vitro and in clinical acquired resistant tumour samples. BMC Cancer 12: 436, 2012

21. Gaudio E, Spizzo R, Paduano F, Luo Z, Efanov A, Palamarchuk A, Leber AS, Kaou M, Zanesi N, Bottoni A, et al: Tcl1 interacts with Atm and enhances NF- $\kappa$ B activation in hematologic malignancies. Blood 119: 180-187, 2012.
22. Svirnovski AI, Serhiyenka TF, Kustanovich AM, Khlebko PV, Fedosenko VV, Taras IB and Bakun AV: DNA-PK, ATM and MDR proteins inhibitors in overcoming fludarabine resistance in CLL cells. Exp Oncol 32: 258-262, 2010.

23. Wu $\mathrm{ZH}$ and Miyamoto S: Induction of a pro-apoptotic ATM-NF-kappaB pathway and its repression by ATR in response to replication stress. EMBO J 27: 1963-1973, 2008.

24. Shiloh Y and Ziv Y: The ATM protein kinase: Regulating the cellular response to genotoxic stress, and more. Nat Rev Mol Cell Biol 14: 197-210, 2013

25. Yang Y, Xia F, Hermance N, Simonson S, Morrissey S, Gandhi P, Munson M, Miyamoto S and Kelliher MA: A cytosolic ATM/NEMO/RIP1 complex recruits TAK1 to mediate the NF-kappaB and p38 mitogen-activated protein kinase (MAPK)/MAPK-activated protein 2 responses to DNA damage. Mol Cell Biol 31: 2774-2786, 2011.

26. Hayden MS and Ghosh S: Shared principles in NF-kappaB signaling. Cell 132: 344-362, 2008

27. Ke SZ, Ni XY, Zhang YH, Wang YN, Wu B and Gao FG: Camptothecin and cisplatin upregulate ABCG2 and MRP2 expression by activating the ATM/NF-kappaB pathway in lung cancer cells. Int J Oncol 42: 1289-1296, 2013.

28. Li F and Sethi G: Targeting transcription factor NF-kappaB to overcome chemoresistance and radioresistance in cancer therapy. Biochim Biophys Acta 1805: 167-180, 2010

29. Straussman R, Morikawa T, Shee K, Barzily-Rokni M, Qian ZR, Du J, Davis A, Mongare MM, Gould J, Frederick DT, et al: Tumour micro-environment elicits innate resistance to RAF inhibitors through HGF secretion. Nature 487: 500-504, 2012.

30. Ning Y, Manegold PC, Hong YK, Zhang W, Pohl A, Lurje G, Winder T, Yang D, LaBonte MJ, Wilson PM, et al: Interleukin-8 is associated with proliferation, migration, angiogenesis and chemosensitivity in vitro and in vivo in colon cancer cell line models. Int J Cancer 128: 2038-2049, 2011.

31. Rohwer N, Dame C, Haugstetter A, Wiedenmann B, Detjen K, Schmitt CA and Cramer T: Hypoxia-inducible factor lalpha determines gastric cancer chemosensitivity via modulation of p53 and NF-kappaB. PLoS One 5: e12038, 2010.

32. Zhu X, Shen H, Yin X, Long L, Chen X, Feng F, Liu Y, Zhao P, $\mathrm{Xu}$ Y, Li M, et al: IL-6R/STAT3/miR-204 feedback loop contributes to cisplatin resistance of epithelial ovarian cancer cells. Oncotarget 8: 39154-39166, 2017.

33. Hazelbag S, Fleuren GJ, Baelde JJ, Schuuring E, Kenter GG and Gorter A: Cytokine profile of cervical cancer cells. Gynecol Oncol 83: 235-243, 2001.

34. Mattei S, Colombo MP, Melani C, Silvani A, Parmiani G and Herlyn M: Expression of cytokine/growth factors and their receptors in human melanoma and melanocytes. Int J Cancer 56: 853-857, 1994.

35. Burke F, Relf M, Negus R and Balkwill F: A cytokine profile of normal and malignant ovary. Cytokine 8: 578-585, 1996.

36. Hoesel B and Schmid JA: The complexity of NF- $\mathrm{KB}$ signaling in inflammation and cancer. Mol Cancer 12: 86, 2013

37. Hill AA, Anderson-Baucum EK, Kennedy AJ, Webb CD Yull FE and Hasty AH: Activation of NF- $\mathrm{BB}$ drives the enhanced survival of adipose tissue macrophages in an obesogenic environment. Mol Metab 4: 665-677, 2015.

38. Chen ZS and Tiwari AK: Multidrug resistance proteins (MRPs/ABCCs) in cancer chemotherapy and genetic diseases. FEBS J 278: 3226-3245, 2011.

39. Doyle L and Ross DD: Multidrug resistance mediated by the breast cancer resistance protein BCRP (ABCG2). Oncogene 22: 7340-7358, 2003.

40. Candeil L, Gourdier I, Peyron D, Vezzio N, Copois V, Bibeau F, Orsetti B, Scheffer GL, Ychou M, Khan QA, et al: ABCG2 overexpression in colon cancer cells resistant to SN38 and in irinotecan-treated metastases. Int J Cancer 109: 848-854, 2004.

41. Yamasaki M, Makino T, Masuzawa T, Kurokawa Y, Miyata $\mathrm{H}$, Takiguchi S, Nakajima K, Fujiwara Y, Matsuura N, Mori M, et al: Role of multidrug resistance protein 2 (MRP2) in chemoresistance and clinical outcome in oesophageal squamous cell carcinoma. Br J Cancer 104: 707-713, 2011. 